\title{
Research for criteria to define the bottom area of assembled foundation of power transmission line in calculation of the compressive load
}

\author{
Cheng Yongfeng ${ }^{\mathrm{a}}$, Zheng Weifeng ${ }^{\mathrm{b}^{*}}$, Lu Xianlong ${ }^{\mathrm{c}}$ \\ Chine Electric Power Research Institute, Beijing 100192, China \\ a Email: cyf@epri.sgcc.com.cn \\ ${ }^{b}$ Email: zhengwf@epri.sgcc.com.cn \\ ${ }^{c}$ Email: luxianlong@epri.sgcc.com.cn
}

\begin{abstract}
Keywords: transmission line; assembled foundation; concrete lath; calculation of compressive load; in-site experiment

Abstract: The assembled foundation of power transmission line, which is composed of concrete lath and angle steel scaffold, has been applied in practice. But due to the gap of laths, the bottom area of the foundation is not clearly defined when calculating the compressive load. Theoretical study on the ultimate bearing capacity of foundation indicates that soil arching effect exists between the adjacent slabs. The in-site experiments at different lath intervals testify that the difference of soil pressures under the laths and at the gap of laths is relatively large in the shallow soil. But the soil pressures are basically the same in the deep layer where the change of the lath interval has no significant impact on soil pressure. The research suggests that the whole area surrounded by the laths is preferable in the calculation of compressive load on the assembled foundation composed of concrete laths.
\end{abstract}

\section{Introduction}

There are a variety of transmission line foundations. The assembled foundation composed of concrete lath and angle steel scaffold (hereinafter referred as "concrete lath foundation") has been tentatively applied to the transmission line project where the natural condition is harsh with scarcity of water and difficulty of collecting construction materials ${ }^{[1 \sim 5]}$. However, because of the interval between concrete laths, while calculating the compressive load of the concrete lath foundation, there is no sufficient theoretical and experimental basis of how to define the bottom area, e.g. only considering the lath area or selecting the whole area surrounded by the laths. Consequently, designers often incline to the conservative approach, which leads to the dense arrangement of laths or the enlarged size ${ }^{[6]}$. For this reason, based on theoretical research and field test, the article explored the principle of how to determine the bottom area of the foundation, providing a technical reference for the application of concrete lath foundation.

\section{Theoretical research}

A single slab of concrete lath foundation can be equivalent to a small strip footing. Its ultimate failure mode can be analyzed by the foundation's ultimate bearing capacity model developed by Prandt ${ }^{[7]}$.As shown in Figure 1, the Prandtl's limit equilibrium area of foundation can be divided into three zones: positive Rankine zone I, passive Rankine zone III, and intermediate zone II . Zone II is a sliding surface composed of a group of rays $\mathrm{AD}$ and of logarithmic spiral curves $\mathrm{CD}$.

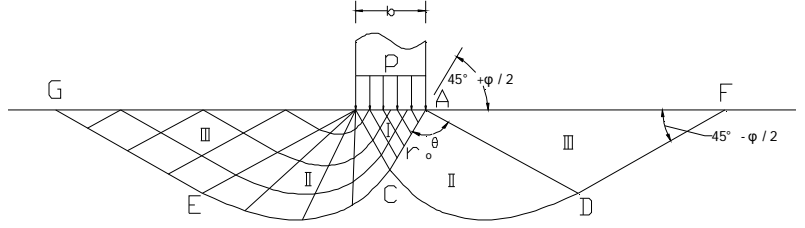

Fig.1 Prandtl's foundation failure mode under overall load 
In limit equilibrium state, the relation of the surface extending distance $L$ of foundation slip surface (the distance from point $A$ to point $F$ in Figure 1 and the internal friction angle $\varphi$ of foundation soil is shown as follows:

$$
L=b e^{\frac{\pi}{2 \tan \varphi \tan \left(45^{\circ}+\varphi / 2\right)}}
$$

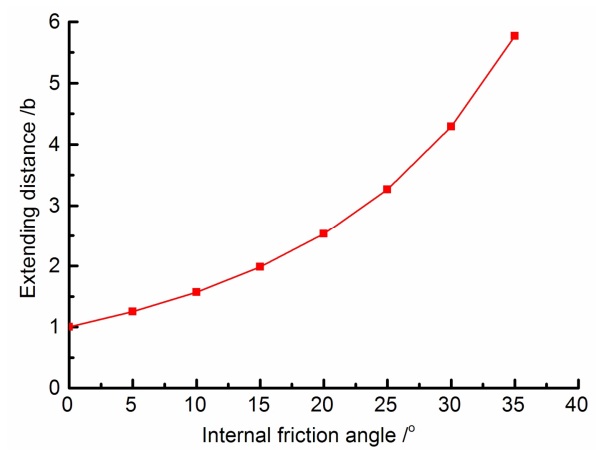

Fig.2 Curve of relation between the surface extending distance of potential slip surface and the internal friction angle of foundation soil

As shown in Figure 2, regardless of the type of soil, the surface extending surface of the potential slip surface is always larger than the interval of laths. According to the experience of design, the clear distance of the laths of concrete lath foundation is generally less than the width of the laths. So the adjacent laths are always within the surface extending distance of the potential slip surface of each other. With the increasing of compressive load, the shape of potential slip surface at the shallow layer of foundation can be estimated, according to the extending trend of plastic zone under the slabs and the stress overlap of the adjacent slabs (see Figure 3). The between two adjacent slabs forms an arched compaction zone. Due to the soil arching effect between laths, the shallow soil under the slab of assembled foundation can be approximately equivalent to a rigid body, which resists the compressive load together with the slabs as a whole.

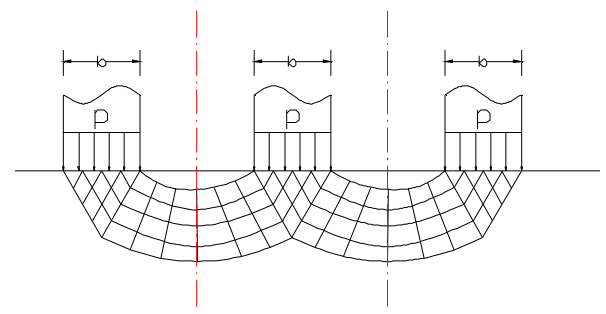

Figure 3 Shape of the potential slip surface of assembled foundation laths at the shallow layer

\section{Field Experiment}

In-site geological conditions. The experiment was arranged in a site of Jixi City, Anhui Province, where the soil is the sandy clay presenting a color of grayish yellow or grayish black. The soil is composed of granite weathering products, with the state from slightly wet to wet and from soft plastic to plastic and fairly soft. Its main physical and mechanical indices are shown in Table 1.

Table 1 Main physical and mechanical indices of local sandy clay

\begin{tabular}{cccc}
\hline $\begin{array}{c}\text { Bulk density } \\
\mathrm{Y} / \mathrm{kN} / \mathrm{m}^{3}\end{array}$ & $\begin{array}{c}\text { Cohesion } \\
\varphi / \mathrm{kPa}\end{array}$ & $\begin{array}{c}\text { Internal friction angle } \\
\varphi /{ }^{\circ}\end{array}$ & $\begin{array}{c}\text { Characteristic value of bearing capacity } \\
f_{a k} / \mathrm{kPa}\end{array}$ \\
\hline 18.5 & 20 & 9 & 10.5 \\
\hline
\end{tabular}

Test plan. The loading tests of the shallow slab with different lath interval are conducted to monitor the variation of the soil pressure in different depths and positions. As shown in Figure 4, the ballasting platform counterforce device is used to exert the load with fast maintained load method. The soil pressure is measured using earth pressure cell. 

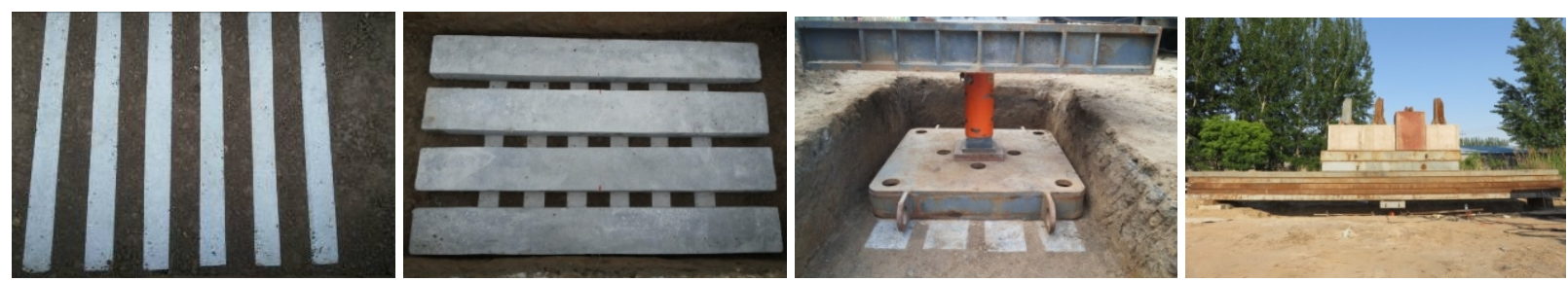

Fig. 4 In-site test of compressive load on the lath

As shown in Figure 5, the lath size is $1 \mathrm{~m}$ in length, $0.1 \mathrm{~m}$ in width and $0.05 \mathrm{~m}$ in height. The intervals of laths are set as $50 \mathrm{~mm}, 100 \mathrm{~mm}$ and $200 \mathrm{~mm}$. The earth pressure cells are arranged in three layers at the depth of $100 \mathrm{~mm}, 300 \mathrm{~mm}$ and $500 \mathrm{~mm}$ below the foundation slab. There are totally nine earth pressure cells in each layer, among which three cells are put at the gap of the laths and the remaining six are symmetrically put under the laths.

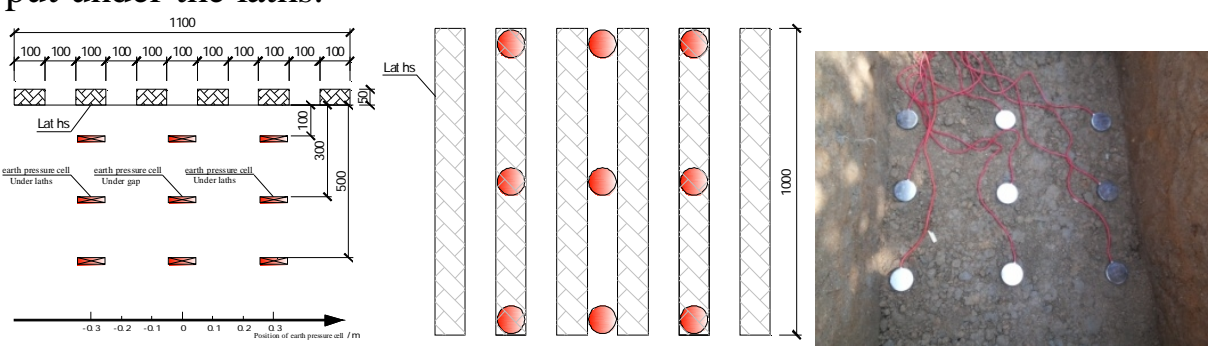

Fig.5 Location of the embedded earth pressure cells

\section{Test results}

Load-displacement curves. The load-displacement curves at different interval of laths $(50 \mathrm{~mm}$, $100 \mathrm{~mm}, 200 \mathrm{~mm}$ ) are shown in Figure 6. It can be seen that although the lath intervals are different, the load-displacement curves are basically identical, with a linear expression. It indicates that the interval of laths has no significant impact on the load bearing performance of the foundation.

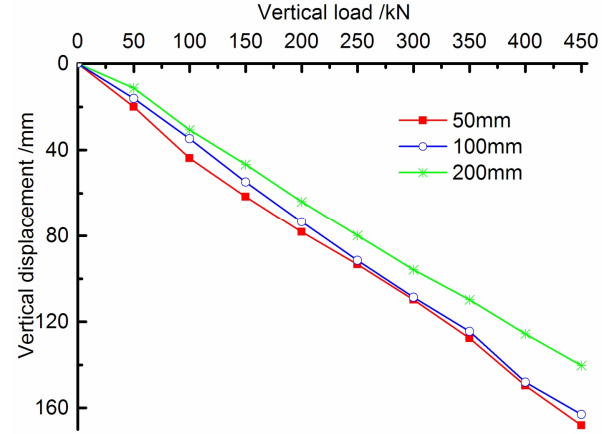

Fig.6 Load-displacement curves at different interval of laths

Variation of soil pressure. The variation of soil pressure in different depths and positions with the enlarging interval of laths $(50 \mathrm{~mm}, 100 \mathrm{~mm}$ and $200 \mathrm{~mm})$ can be observed from Figure 7,8 and 9 . Table 2 lists the ratios of the difference of soil pressure at different lath intervals under the maximum compressive load. Through the comparison of variations of soil pressure in Figure 7 to Figure 9, the following rules are summarized:

1) With the increasing of compressive load, the soil pressure increases.

2) The average pressure on the slab is larger than the measured soil pressure.

3) In the deeper soil, due to the effect of pressure diffusion, the soil pressure becomes smaller.

4) When the depth is relatively shallow $(-100 \mathrm{~mm})$, the soil pressure at the gap of the laths is significantly smaller than that under the laths, with the maximum ratio of pressure difference reaching 99\%. With the buried depth gradually increasing, the soil pressures at three monitoring points tend to be consistent overall. Especially when the buried depth reaches $-500 \mathrm{~mm}$, the soil pressures at three monitoring points are basically equal, and the maximum ratio of pressure difference is only $3 \%$.

5) For the lath intervals of $50 \mathrm{~mm}, 100 \mathrm{~mm}$ and $200 \mathrm{~mm}$, the above rules of pressure variation basically keep the same. 
The results of in-site experiment show that in the shallow soil $(-100 \mathrm{~mm})$, the soil pressure at the gap of laths is smaller than that under the laths. With the depth increasing $(-300 \mathrm{~mm})$, the soil pressures at the gap of laths and under the laths incline to be equal. When the depth reaches a certain value ( $-500 \mathrm{~mm})$, there is no difference between soil pressures. Moreover, the variation of lath interval has no significant impact on the deep soil pressure.
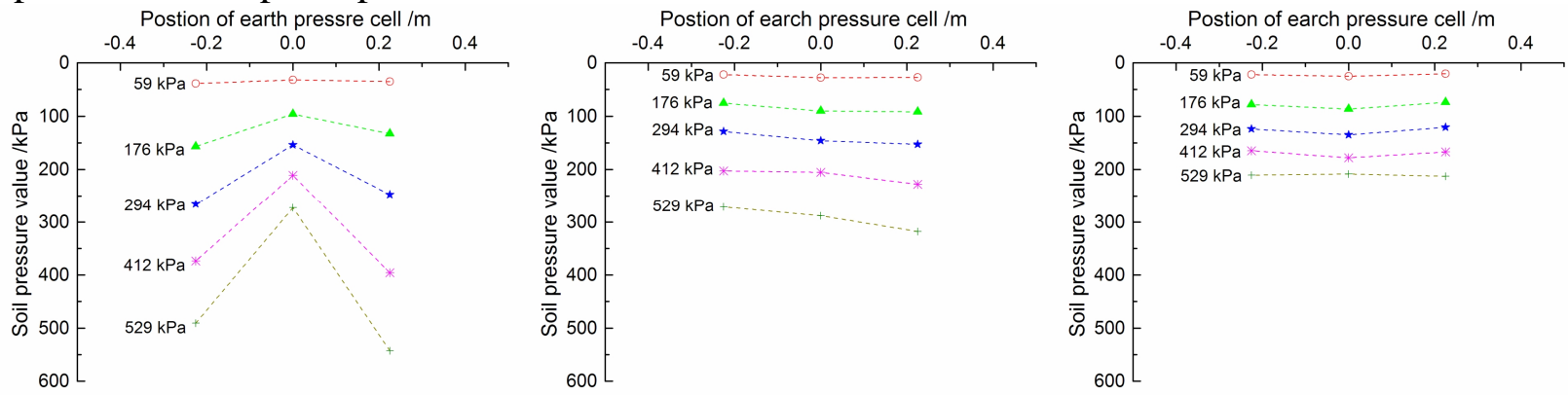

(a) -100mm depth under the bottom (b) -300mm depth under the bottom (c) -500mm depth under the bottom

Fig.7 Variation of soil pressure with depth and position at the lath interval of 50mm
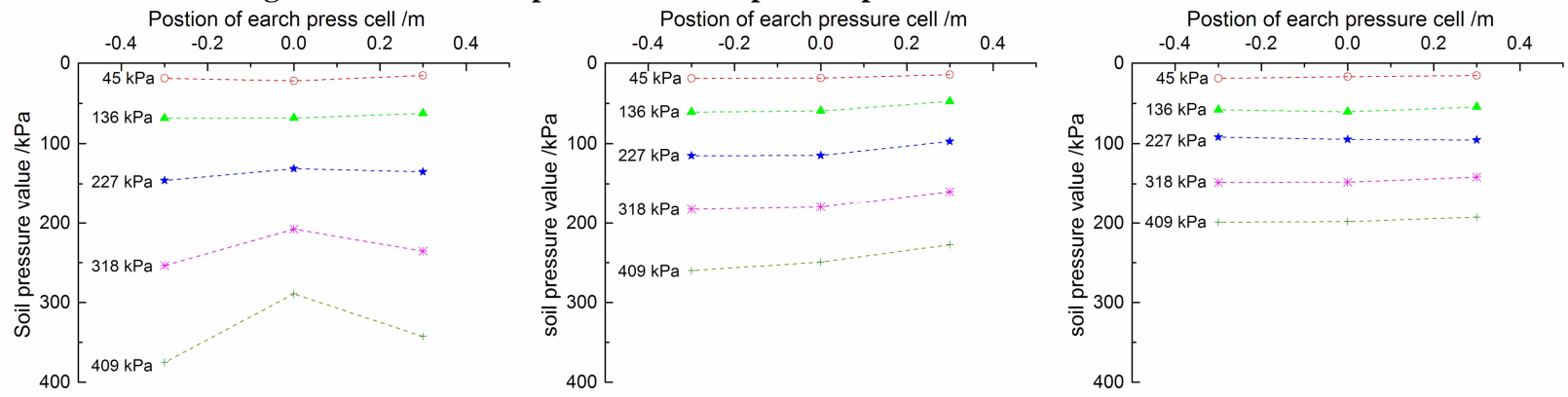

(a) -100mm depth under the bottom (b) -300mm depth under the bottom (c) -500mm depth under the bottom

Fig.8 Variation of soil pressure with depth and position at the lath interval of $100 \mathrm{~mm}$
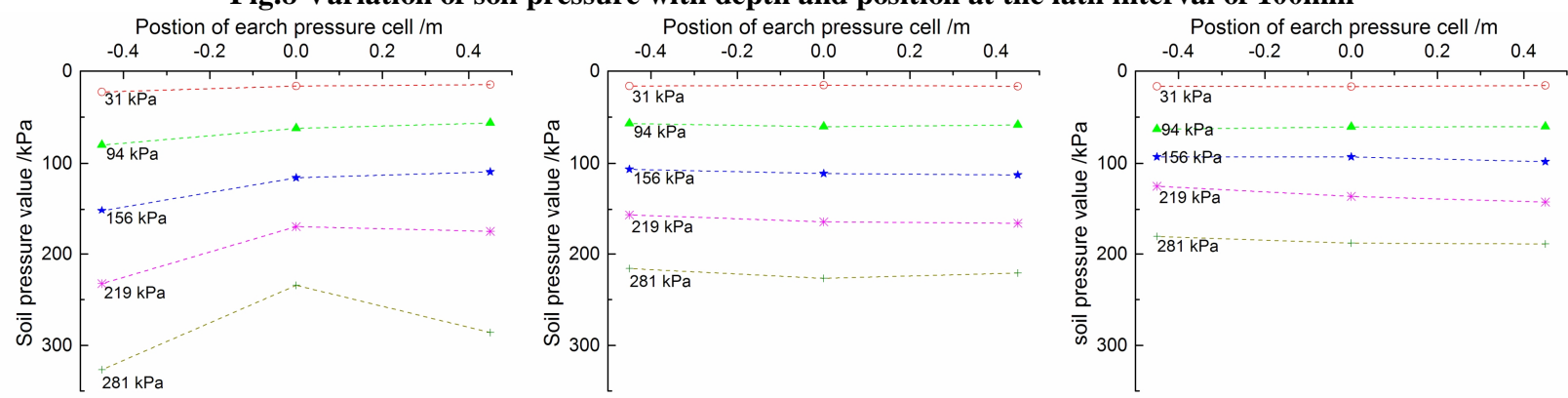

(a) -100mm depth under the bottom (b) -300mm depth under the bottom (c) -500mm depth under the bottom

Fig.9 Variation of soil pressure with depth and position at the lath interval of $200 \mathrm{~mm}$

Table 2 Ratios of soil pressure difference under the maximum compressive load at different interval of laths

\begin{tabular}{|c|c|c|c|c|c|c|}
\hline \multirow{2}{*}{$\begin{array}{l}\text { Interval of the laths } \\
\text { Position of earth pressure cell }\end{array}$} & \multicolumn{2}{|c|}{$50 \mathrm{~mm}$} & \multicolumn{2}{|c|}{$100 \mathrm{~mm}$} & \multicolumn{2}{|c|}{$200 \mathrm{~mm}$} \\
\hline & $\begin{array}{l}\text { Average } \\
\text { pressure }\end{array}$ & $\begin{array}{l}\text { Difference of } \\
\text { soil pressure }\end{array}$ & $\begin{array}{l}\text { Average } \\
\text { pressure }\end{array}$ & $\begin{array}{l}\text { Difference of } \\
\text { soil pressure }\end{array}$ & $\begin{array}{l}\text { Average } \\
\text { pressure }\end{array}$ & $\begin{array}{l}\text { Difference of } \\
\text { soil pressure }\end{array}$ \\
\hline$-100 \mathrm{~mm}$ & \multirow{3}{*}{$529 \mathrm{kPa}$} & $99 \%$ & \multirow{3}{*}{$409 \mathrm{kPa}$} & $30 \%$ & \multirow{3}{*}{$281 \mathrm{kPa}$} & $40 \%$ \\
\hline$-300 \mathrm{~mm}$ & & $10 \%$ & & $-9 \%$ & & $-5 \%$ \\
\hline$-500 \mathrm{~mm}$ & & $2 \%$ & & $-3 \%$ & & $-1 \%$ \\
\hline
\end{tabular}

\section{Conclusions}

(1) Theoretical study on the ultimate bearing capacity of foundation soil indicates that, due to the small interval of the laths of concrete lath foundation (not larger than the width of slab), there exists soil 
arching effect between the adjacent slabs when a compressive load is exerted. So the shallow soil under the slab can be regarded as a rigid body and calculated together with the slab as a whole.

(2) The in-site experiments at various lath intervals testify that, due to the effect of pressure diffusion, the difference of soil pressures under the laths and at the gap of laths is relatively large in the shallow soil. But they are basically equal in the deep layer where the change of lath interval has no significant impact on soil pressure.

Based on the actual arrangement of laths (the interval of laths is related with the properties of soil) for the assembled foundation composed of concrete lath and angle steel scaffold in power transmission line engineering, it is suggested to use the whole area surrounded by the laths to calculate the compressive load on the foundation slab.

This paper is supported by fund of Science and Technology Project of State Grid Corporation of China (GCB17201400134).

\section{References}

[1] Lu Xianlong, Cheng Yongfeng, Ding Shijun. Property of aeolian sand and design of the uplift bearing capacity for the sand foundation of transmission line structures. Electric Power Construction, 2010,31 (7): 46-50.

[2] Qian Zengzhen, Lu Xianlong, Ding Shijun. Experimental study of assembly foundation for transmission line tower in Taklimakan desert. Rock and Soil Mechanics, 2011,32 (8): 2359-2365.

[3] Cheng Yongfeng, Ding Shijun. Prototype tests of assembled foundation of transmission line in aeolian sand area. Rock and Soil Mechanics, 2012,33 (11): 3230-3236.

[4] China Electric Power Research Institute. Investigation on the application of assembled foundation of transmission line tower. China Electric Power Research Institute, Beijing, 2013

[5] Department of Infrastructure of State Grid Corporation of China. Mechanized construction technology of transmission lines: design section. China Electric Power Press, Beijing, 2015.

[6] Industry Standard of the People's Republic of China. Technical specification for designing foundation of overhead transmission lines (DL/T 5219-2014). China Electric Power Press, Beijing, 2014.

[7] Guo Ying, Guo Chengkan, Lu Shangmo. Soil Mechanics. Dalian University of Technology Press, Dalian, 2003. 